\title{
The future of paediatric cardiology in the United Kingdom
}

Report of a joint working party of the British Cardiac Society and the Royal College of Physicians of London

\section{Introduction}

This committee was formed as a result of a perceived crisis in consultant staffing in paediatric cardiology in the United Kingdom. Though an imbalance between the numbers in training and the available consultant positions is probably endemic to the National Health Service (even with the Joint Planning Advisory Committee), the situation which confronted the profession in 1987 and 1988 was very worrying. Two newly constituted consultant posts in paediatric cardiology and two existing posts were unfilled because there were no suitably trained applicants.

The British Cardiac Society and the Royal College of Physicians set up this working party in 1988 to look at the causes of the problem and to make recommendations for the future. The working party took a wide view of its remit and recognised that the training needs of paediatric cardiologists and the projected numbers needed by the profession in the next ten years contributed to the problem.

\section{Training of a paediatric cardiologist}

(These recommendations are now incorporated into the Joint Committee on Higher Medical Training Guidelines 1989.) Paediatric cardiology is now practised almost exclusively in regional and supraregional centres with two or more consultant paediatric cardiologists and the supporting staff and equipment required to diagnose and treat cardiac conditions in children, most of which are congenital. Some, but not all such centres, are associated with general and other specialised paediatrics. It is essential that paediatric cardiologists have adequate training in paediatrics to allow care of the whole child. In addition, training is needed in the two growing areas of paediatric cardiology - care of the adolescent and adult with congenital heart disease and diagnosis and management of fetal cardiac abnormalities.

\section{GENERAL PROFESSIONAL TRAINING}

Before embarking on the specialised part of their training paediatric cardiologists will usually have obtained the MRCP or an equivalent qualification, either in paediatrics or in medicine. Training should include paediatrics or cardiology.
HIGHER SPECIALIST TRAINING

At some stage during an individual's training either general, professional or higher specialist, it is normally required that 6-12 months should be spent in adult cardiology and one to two years in paediatrics including six months in a neonatal unit, preferably a regional referral unit. Flexibility is accepted and expected. The normal training period for paediatric cardiologists should be increased from four to six years. At least four years should be in a specialist paediatric cardiological centre dealing with all forms of heart diseaser including neonatal and infant, and investigation of the fetal heart and circulation. Liaison with other paediatric specialties and adult cardiology should be encouraged during this period. Experience in the intensive care of paediatric cardiac surgical patients is essential. During the training period certain aspects of cardiology may need to be obtained by exposure to the adult branch of the specialty-for example, pacing, management of arrhythmias, exercise testing, and nuclear cardiology. Trainees should spend the equivalent of one year in cardiovascular research.

A joint group (under the chairmanship of Dr Douglas Chamberlain) representing the Specialty Advisory Committee and the Committee on Cardiology of the Royal College of Physicians of London and the British Cardiac Society has recently proposed a new scheme of training for adult cardiologists. ${ }^{1}$ This consists of three years general professional training (senior house officer and registrar level), three years of high professional training at registrar level, and at least three years at senior registrar level. The working party's recommendations for paediatric cardiologists are not incompatible with these proposals although the current lack of registrar positions in paediatric cardiology in the United Kingdom presents an obvious problem.

The Association of European Paediatric Cardiologists is also studying the training of young consultants with a view to achieving some degree of unanimity by 1992 . Preliminary information suggests that our recommendations would also fit with the European plan.

We recommend that paediatric cardiologists should have a minimum of three years general professional training after registration followed 
by three years of higher professional training at registrar level and a further three years at senior registrar level. Ideally one year should be spent in research during this period.

\section{Previous reports on paediatric cardiological services}

REPORT OF THE BRITISH PAEDIATRIC ASSOCIATION WORKING PARTY ON CARDIAC SERVICES FOR CHILDREN IN ENGLAND AND WALES

This unpublished report, prepared in February 1979 by O P Gray, T P Mann, M J Simpkiss, M C Joseph, R S Jones, and G H Watson, carefully documented the position in the 1970s. The report was concerned because there were too many small units that lacked the facilities essential for successful treatment of children with congenital heart disease. It emphasised that all staff should have paediatric training and particular expertise in handling the newborn. Improvements in ancillary services including specialist physiotherapy, social work, and parental accommodation were identified and recommended. Other improvements in invasive and non-invasive investigational services and provision of dedicated surgical theatres were identified and recommended.

This working party strongly advised that paediatric cardiology was better practised in a large children's hospital or in a children's department of sufficient size in a general hospital with the corresponding regional cardiac unit adjacent to the children's unit. Most of the centres in England and Wales fulfil one or other of these criteria. The British Paediatric Association's report recommended that there should be two major units in the London area and that there should be four large centres outside it to provide services for Bristol and Cardiff, Liverpool and Manchester, Leeds and Sheffield, and Birmingham. Geographical consideration suggested that Newcastle and Southampton should continue as separate smaller units.

Much of the philosophical content of the British Paediatric Association report is still important and appropriate. The major centres have by and large been suitably developed. A Welsh centre is shortly to be established to provide a total service for the children of South and Mid Wales. The service is likely to develop to provide adequate country wide cover.

THE SECOND AND THIRD REPORTS OF THE JOINT CARDIOLOGY COMMITTEE OF THE ROYAL COLLEGE OF PHYSICIANS OF LONDON AND THE ROYAL COLLEGE OF SURGEONS OF ENGLAND $1980^{2}$ AND $1985^{3}$

These two reports examined the provision of overall cardiac services and staffing throughout England and Wales and dealt with paediatric cardiology as a part of this whole.

The second report used data from the New England Regional Infant Cardiac Programme and from the Joint Committee on Higher Medical Training and Joint Committee on
Higher Surgical Training to make several recommendations, some of which are still appropriate today. The report argued strongly for specialisation in paediatric cardiac surgery with its increasing emphasis on correction in infancy. The skills needed should be concentrated in a few centres and supported by a central fund. The report also recommended that the needs of older paediatric cardiac surgical patients should be met within the same units. Each unit was to have two consultant cardiothoracic surgeons and two or three consultant paediatric cardiologists, all of whom would participate in the cardiological care of the younger and the older patients with congenital heart disease. Recognition as a supraregional centre was to be based not just on workload and geographical location but also on the quality of the work done. To date no real audit of surgical results is available and surgical needs are still based purely on the number of patients undergoing operation. The recommendations of the report for paediatric cardiology outside supraregional centres were vague and suggested some form of joint care by cardiologists and paediatricians.

The third report in 1985 perpetuated the separation of surgical care for patients under one year of age and patients over one year of age. The report referred to the recently endorsed and established nine supraregional centres in Birmingham, Bristol, Brompton Hospital, Great Ormond Street, Guy's Hospital, Leeds, Liverpool, Newcastle, and Southampton. The report suggests that there should be no more than nine centres. In choosing this figure the authors of the report obviously followed the Black Committee recommendations, which were partly based on a desire to improve standards but were also designed to limit the spread of the specialty and cut costs. The 1985 report recommended that such supraregional centres should also treat older children with heart disease. Supraregional centres were said to require a minimum of two surgeons to maintain 24 hour year round cover and between two and four paediatric cardiologists.

The reality of paediatric cardiological practice at the moment is a little different from the conclusions of the third report. The number of consultant paediatric cardiologists has indeed increased in the supraregional centres. But few supraregional centres have two full time paediatric cardiac surgeons. While the concept of supraregional funding for infant cardiac surgery is working well, the medical and surgical care of the older child and adolescent has not been planned nationally but has been left to chance development. The working party believes that we need a national plan to provide a service for this increasingly important group.

\section{Paediatric cardiological services in the next decade}

The British Paediatric Association working party in 1979 based its predication of future services on reports of the incidence of congenital heart disease from North America and Australia. They chose a figure of seven or eight 
per 1000 live births and there is no reason to believe that this figure will change in the near future. It will be a long time before prenatal diagnosis affects the number of patients with serious malformations who reach the paediatric cardiologist.

The present working party tried to estimate the caseload of paediatric cardiological centres to the end of the century based on population trends and predictions from the Department of Health. The method of prediction is not entirely clear and probably not entirely uniform throughout the United Kingdom. Several of the northern regions predict a $0-3 \%$ increase in the number of children under 14 years by the year 2001, whereas Wessex predicts an increase of up to $22 \%$. Taking the predictions for the country as a whole there will be an increase in the total number of children under 14 years of between $9 \%$ and $10 \%$ by the year 2001. Assuming that the incidence of congenital heart disease remains static then the service will have to cope with a very considerable increase in patient load in the next decade.

At the present time there are 48 full time or maximum part time paediatric cardiological posts in the United Kingdom. Vacancy and retirement will necessitate consultant appointments being made to existing positions by the year 2001. If this working party's recommendations for growth are accepted then a further ten new posts will be required by 2001 (see recommendation [a]). Candidates for these positions must come at present from six senior registrar positions in the United Kingdom (two more have been provisionally agreed but not yet implemented). There is no infrastructure of middle grade registrar posts in paediatric cardiology to supply suitable candidates for these senior registrar positions. There are only three full time middle grade registrar posts in paediatric cardiology at the Hospital for Sick Children, Great Ormond Street, and one at the Royal Brompton National Heart and Lung Hospital. Nine further centres have one registrar who is part of either an adult cardiological or a paediatric rotation. Most of them will not become paediatric cardiologists.

The immediate shortfall in trained candidates for consultancies cannot be overcome by planning. On the other hand it was unrealistic to insist that senior registrars spend four years in training before being appointed to consultancies. Regional health authorities should be encouraged to identify suitable though inexperienced candidates for proleptic appointments with secondment to other centres to complete their training.

The existing posts for senior registrars may provide sufficient suitably trained applicants for existing consultancy vacancies during the 90 s but they will not allow for any expansion. On the basis of increased consultant posts alone, therefore, an increase both in senior registrar and registrars is obviously indicated.

Factors affecting the workload patterns of paediatric cardiologists

Since the previous reports the specialty has undergone remarkable changes as a result of technological advances. Congenital heart disease is now diagnosed and treated in prenatal and in adult life in a way that was unthinkable two decades ago.

Specialists in adult cardiology are now more heavily committed to the treatment of ischaemic heart disease than ever before. They have neither time nor unfortunately the "know how" to cope successfully with the increasing number of adults with congenital heart disease. Accurate data on the case load of adult and adolescent patients with congenital heart disease are not at present easy to come by. While as many as 20000 patients probably need cardiological supervision into adult life in the United Kingdom, an estimated 700 per annum with complex problems will require some form of cardiac surgery or intervention. The problem is bound to become increasingly important. Care of this group may fall to the paediatric cardiologist or to the specialist in adult cardiology with suitable experience. The most suitable choice will depend on the local situation. Services need to be planned centrally for the whole country. The working party strongly believes cardiologists to treat this special group of patients should be trained in existing supraregional paediatric cardiological centres where expertise in adult cardiology is also available. Because few patients will be requiring active intervention supraregional funding arrangements would be appropriate.

Interventional procedures are now commonplace in the treatment of congenital heart disease. Aortic valve stenosis, pulmonary valve stenosis, and coarctation and recoarctation of the aorta are all often well treated by means other than surgery as the first line of attack. Despite the impact of non-invasive techniques, the number and complexity of invasive paediatric cardiological procedures are actually increasing and will continue to do so for the foreseeable future as interventional procedures become more commonplace.

There is a trend for paediatric cardiological centres to be established as regional clinics. Because many of the regions are so large patients may have to travel 100 and more miles to the regional centre. It is usual for at least one of the paediatric cardiological team to be out of the regional centre attending a peripheral clinic every week. The peripheral clinic needs to be built into job descriptions and the implications for staffing numbers needs to be considered.

Prenatal diagnosis, as pioneered at Guy's Hospital, is fast becoming part of the everyday work of the regional and supraregional paediatric cardiological unit. It is time consuming and technically difficult. Realistically only the paediatric cardiologist has the knowledge to use the information that prenatal diagnosis gives to advise on the continuation or termination of pregnancies when congenital heart disease is diagnosed in the fetus. The working party strongly believes that this new discipline must be recognised as part of the work of a paediatric cardiologist. The specialist nature of the scanning and counselling means that it is a regional or supraregional centre activity and ought to be funded on a supraregional or regional base by protected funds. 
Recommendations

The recommendations that follow are based on existing work patterns and population predictions. If the implications of "Achieving a Balance" are ever realised then the staffing requirements of the specialty would be significantly increased even over the changes suggested in this document. At present, paediatric cardiological centres, whether supraregional or regional, serve populations of on average three million people. For historical reasons some of the larger centres serve more than five million people. It is impossible to assess the true population drained by the London centres because of their local situation and referral patterns.

(a) Building on recommendations of the other working parties, this committee acknowledges the change and growth in the work patterns and caseload of the paediatric cardiologist and recommends a minimum of one consultant paediatric cardiologist per million of the population. This means that no unit should have less than three consultants, bringing the speciaty into line with general Department of Health recommendations at present applied to other grades of hospital doctor. The working party thinks that this recommendation is of great importance in a consultant orientated specialty such as paediatric cardiology. The implications of this recommendation in terms of future new jobs are considerable. The total number of posts throughout the United Kingdom will rise from 48 (41 existing posts in England and Wales, two in Northern Ireland, and five in Scotland) to between 55 and 60.

(b) This increase in consultants cannot possibly be filled from existing senior registrar posts and the working party therefore recommends that every supraregional centre should support a senior registrar training post and at least two middle grade registrars full time in paediatric cardiology. An increase of at least three senior registrars is needed. Two such posts have been provisionally agreed by the General Purposes Sub-Committee 1990 of the Joint Planning Advisory Committee. The working party believes that the provision of middle grade registrar posts is crucial to the provision of suitable experienced candidates to fill the senior registrar posts.

(c) The working party acknowledged the usefulness of supraregional arrangements for funding infant cardiac surgery in existing centres. This problem has been addressed and largely solved. Now the profession and central planners need to recognise the vital expansion of paediatric cardiology into prenatal and young adult life. These developments are as important as infant cardiac surgery and need careful central planning and protected funding.

\section{Summary}

(1) The working party has considered the requirements for the training of paediatric cardiologists and has suggested a flexible curriculum that allows the specialty to benefit from doctors coming into it from both adult cardiological and paediatric disciplines.

(2) The working party appreciates that the short term problem with appointment of paediatric cardiologists cannot be solved immediately and recommends that appointing authorities should show patience. They should look to the possibility of identifying suitable candidates, at present in training, and making proleptic appointments to allow appropriate training to be completed.

(3) There is a need for an increase in the number of paediatric cardiologists to service the specialty during a period when the patient load will increase because of population trends and changes in work patterns (specifically adults with congenital heart disease and prenatal cardiology). The care of adults with congenital heart disease has to be planned, certainly at regional and probably supraregional levels, and the financial and training implication has to be recognised.

(4) The working party therefore recommends that there should be one consultant paediatric cardiologist per million of the population to allow for these changes in the service.

(5) The working party considers that this report makes a very strong case for an increase in the number of senior registrar and registrar posts in the specialty. The existing number of junior posts will not fill the increase in agreed new posts and those made vacant by retirements between now and the end of the decade. When the additional posts recommended by the working party are taken into account at least three new senior registrar posts are needed. To make sure that a satisfactory supply of experienced candidates is available to fill the senior registrar posts the working party recommends the provision of two full time middle grade registrar jobs for each senior registrar position.

1 Joint Training and Manpower Group representing the Specialty Advisory Committee and the Cardiology Committee of the Royal College of Physicians of London, and the British Cardiac Society. Proposals for a new training

2 programme for cardiology. Br Heart J 1990;63:317-20. Second report of a Joint Cardiology Committee of the Royal College of Physicians of London and the Royal College of Surgeons of England on combined cardiac centres for investigation and treatment with a note on the requirements of cardiology in hospitals outside such a centre. Br Heart J 1980;43:211-9.

3 Third report of a Joint Cardiology Committee, Roya College of Physicians of London and the Royal College of Surgeons of England. Provision of services for the diagnosis and treatment of heart disease in England and Wales. Br Heart $J$ 1985;53:477-82. 